\title{
Implications of long-term superphosphate applications on the accumulation and plant availability of soil phosphorus under irrigated pastures
}

L.M. CONDRON and K.M. GOH

Soil Science Department, Lincoln University

\begin{abstract}
Changes in soil phosphorus (P) associated with the establishment and maintenance of improved ryegrass-clover pasture under different superphosphate fertiliser treatments were examined over a 20-year period (1957-77). Results showed that soil organic $\mathrm{P}$ increased with increasing applications of $\mathrm{P}$ fertiliser. This represents a dynamic balance between rates of organic $\mathrm{P}$ addition and breakdown in the soil. This balance is reached slowly and may be significantly altered only by drastic changes in land use. In annually fertilised soils, amounts of inorganic $\mathrm{P}$ increased with time. However, the potential utilisation of this residual inorganic $\mathrm{P}$ is limited by its apparent stability in the soil.
\end{abstract}

Keywords grazed pasture, irrigation, fertiliser $\mathrm{P}$, soil inorganic $\mathrm{P}$, soil organic $\mathrm{P}$, soil $\mathrm{P}$ fractionation

\section{Introduction}

The low native phosphorus $(\mathrm{P})$ status and high $\mathrm{P}$ retention characteristics of many New Zealand soils necessitate regular applications of $\mathrm{P}$ fertiliser to establish and maintain improved grass-clover pasture. On an annual basis, the amount of $\mathrm{P}$ removed from soil under pasture in off-farm produce and by stock transfer is equivalent to only $\mathbf{1 0 - 5 0 \%}$ of the $\mathrm{P}$ applied in fertiliser (Parfitt 1980). As a direct -result of continued- -applications of $\mathrm{P}$ fertiliser, considerble accumulations of $\mathrm{P}$ have been observed in established grassland soils in New Zealand (Jackman 1964; Condron \& Coh 1989). In recent years, P fertiliser application to pastures in New Zealand has declined dramatically in response to lower product returns and the removal of direct subsidies. Under these circumstances, residual P accumulated in the soil from previous fertiliser additions may play an important role in plant $\mathrm{P}$ nutrition (Mackay \& Wewala 1990).

The main objective of this paper is to describe aspects of recent research on $\mathrm{P}$ accumulation in fertilised pasture soils and highlight some important limitations of the potential utilisation of residual $\mathrm{P}$ by pasture plants.

\section{Methods}

Soils were obtained from the long-term superphosphate (SSP) trial situated at the Winchmore Irrigation Station in Mid-Canterbury (Condron \& Goh 1989; Nguyen et al. 1989). This particular trial is the longest running experiment of its kind in New Zealand. The present study was concerned with changes in soil $\mathrm{P}$ which occurred between 1958 and 1977 in the following treatments: control (420 kg SSP/ha 1948-51, none 1952-77) 188PA (420 kg SSP/ha 1948-51, $188 \mathrm{~kg}$ SSP/ha/yr 1952-77)

376RES (420 kg SSP/ha 1948-51, $376 \mathrm{~kg}$ SSP/ha/yr 1952-57, none 1958-77)

Soil samples $(\mathrm{O}-75 \mathrm{~mm})$ collected from these treatments in 1958, 1968 and 1977 were subjected to soil $\mathrm{P}$ analysis which involved sequential extractions to_(i)_determine -total inorganic-P-(Pi)-and-organic $\quad P$ (Po), and (ii) separate and identify different forms of inorganic and organic P (Condron \& Goh 1989). For the purpose of this study the different $\mathrm{P}$ fractions were assigned the following relative plant availabilities:

- available Pi $\mathrm{NaHCO}_{3}$ and $\mathrm{NaOHI}$ extractable $\mathrm{Pi)}$

- stable Pi (HCI and NaOHII extractable Pi)

- labile Po ( $\mathrm{NaHCO}_{3}$ extractable PO)

- stable Po (NaOHI and NaOHII extractable Po).

\section{Results and discussion}

Amounts of total soil Pi increased in the 188PA treatment between 1958 and 1977 and decreased in the control and 376RES treatments between 1958 and 1968 (Table 1). On the other hand, total soil Po increased in all 3 treatments between 1958 and 1968, substantially more so in the fertilised treatments (188PA, 376RES) than in the control (Table 1).

\section{Organic $P$}

Accumulations of $\mathrm{Po}$ in soil with time under pasture (Table 1) reflect increases in overall biomass production and microbial activity in the soil which 
Table 1 Amounts (mg $\mathrm{P} / \mathrm{kg}$ ) of total inorganic $\mathrm{P}(\mathrm{Pi})$ and organic $(\mathrm{Po})$ in soils from the control, 188PA and 376RES treatments sampled in 1958, 1968 and 1977.

\begin{tabular}{|c|c|c|c|c|c|c|}
\hline & \multicolumn{2}{|c|}{1958} & \multicolumn{2}{|c|}{1968} & \multicolumn{2}{|c|}{1977} \\
\hline & $\mathrm{Pi}$ & Po & $\mathrm{Pi}$ & Po & $\mathrm{Pi}$ & P 0 \\
\hline control & 238 & 348 & 225 & 373 & 224 & 360 \\
\hline 188PA & 266 & 371 & 291 & 443 & 319 & 439 \\
\hline 376RES & 308 & 371 & 253 & 421 & 261 & \\
\hline
\end{tabular}

result from improved soil moisture (from irrigation) and nutrient availability (especially $\mathrm{P}$ and $\mathrm{N}$ ) (Jackman 1964; Condron \& Goh 1989). Nonetheless, soil Po increased in the 376RES treatment after 1958 in the absence of continued $\mathrm{P}$ fertiliser inputs despite a dramatic decline in pasture production (Figure 1). This suggests that despite decreased plant $\mathrm{P}$ uptake and consequent returns of $\mathrm{P}$ in organic residues in the 376RES treatment, the effective rate of $\mathrm{Pi}$ immobilisation exceeded the corresponding rate of Po mineralisation over the 1958 to 1968 period. This finding demonstrates the dynamic nature of PO transformations in recently improved pasture soils and the time required to reach the appropriate equilibrium or steady-state condition. The influence of greater inputs of soluble $\mathrm{P}$ fertiliser on the final equilibrium level of soil organic $\mathrm{P}$ is evident in the 188PA soil sampled in 1977 (i.e. >376RES) (Table 1).

The elevated organic $\mathrm{P}$ content of the fertilised soils effectively represents a dynamic balance between the respective rates of $\mathrm{Pi}$ immobilisation and Po mineralisation, and as a result organic $\mathrm{P}$ has limited value as an "exploitable" $\mathrm{P}$ resource.

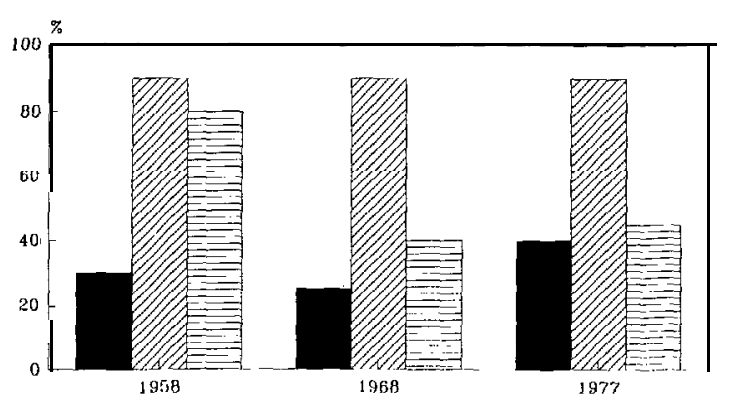

1)M Yicld $(376 \mathrm{PA}=100 \%)$

control $\mathbb{Z A} 1$ 188PA $E \exists$ 376Res

Figure 1 Relative dry matter yields for the control, 188PA and 376RES treatments in 1958, 1968 and 1977 $(376 \mathrm{PA}=100 \%)$
Nonetheless, soil management practices can disturb this balance. For example, the addition of lime to regularly fertilised pasture soils can result in some net mineralisation of Po, although the overall effect is often very small and, short-lived as soil $\mathrm{pH}$ and exchangeable bases decline again with time (Oniani et al. 1973; Condron \& Goh 1989; Perrott \& Manse11 1989). The Winchmore trial was limed in 1972 which may partly account for the small net decreases in organic $\mathrm{P}$ evident in the control and 376RES treatments between 1968 and 1977 (Table 1). On the other hand, more drastic changes in land use such as the long-term cultivation of grassland soils dramatically alters Po cycling and often results in a marked decline in soil Po (Stewart \& Tiessen 1987).

The recent origin of most of the organic matter in the Winchmore soils is reflected in the distribution of soil PO. Thus proportionate increases in soil PO caused by fertiliser addition were greater in the labile pool than in more stable forms of Po. For example, in soils sampled in 1968 the increases in labile Po and stable $\mathrm{Po}$ in the 188PA treatment compared with the control were $34 \%$ and $17 \%$ respectively (Table 2).

\section{Inorganic $\mathrm{P}$}

The decline in soil Pi which occurred in the 376RES treatment after 1958 (Table 1 and 2) may be attributed to the utilisation of residual $\mathrm{P}$ from previous $\mathrm{P}$ fertiliser applications (1948-1957). The concomitant increase in soil Po which occurred in this treatment (Table 1) suggests that a signficant proportion of the residual $\mathrm{Pi}$ was converted to organic $\mathrm{P}$ forms in the soil.

Despite the fact that in 1977 amounts of available and stable $\mathrm{Pi}$ were greater in the 376RES soil than in the control (Table 2), the respective pasture yields for that year were very similar (Figure 1). This clearly illustrates the limited plant availability of residual $\mathrm{Pi}$ in soil which may be partly due to the increased stability of fertiliser P-soil colloid reaction products with time (Devine et al. 1968). This was confirmed in glasshouse and field experiments carried out on the Winchmore long-term trial by Goh \& Condron (1989) and Condron \& Goh (1990).

\section{Conclusions}

Fertiliser $\mathrm{P}$ applied during the early stages of improved pasture development contributes to the accumulation of organic $\mathrm{P}$ in the soil. Data from the Winchmore long-term trial show that at the optimum $\mathrm{P}$ application rate (i.e. 188PA treatment), the

Table 2 Amounts (mg P/kg) of available Pi (AVPi), stable Pi (SPi), labile Po (LPo) and stable Po (SPo) in soils from the control, 188PA and 376RES treatments sampled in 1958, 1968 and 1977.

\begin{tabular}{|c|c|c|c|c|c|c|c|c|c|c|c|c|}
\hline & \multicolumn{4}{|c|}{1958} & \multicolumn{4}{|c|}{1968} & \multicolumn{4}{|c|}{1977} \\
\hline & AVPi & $\mathrm{SPi}$ & LPo & $\mathrm{SPo}$ & AVPi & $\mathrm{SPi}$ & LPO & SPo & AVPi & SPi & LPo & $\mathrm{SPo}$ \\
\hline control & 128 & 110 & 42 & 306 & 116 & 109 & 44 & 329 & 109 & 115 & 41 & 319 \\
\hline 188PA & 148 & 118 & 48 & 323 & 159 & 132 & 59 & 384 & 154 & 165 & 59 & 380 \\
\hline 376RES & 168 & 140 & 51 & 320 & 135 & 118 & 50 & 371 & 128 & 133 & 51 & 350 \\
\hline
\end{tabular}


accumulation of residual $\mathrm{Pi}$ in soil becomes significant only once the equilibrium level of soil Po has been reached (i.e. once continued net accumulation of Po in soil has effectively ceased after around 20 years). However, constraints on the long-term availability of residual $\mathrm{Pi}$ in soil (ref. 376RS) mean that while it may be possible to reduce $\mathrm{P}$ fertiliser application rates in established grassland, continued additions of $\mathrm{P}$ fertiliser will be required to maintain a consistent level of pasture production.

\section{ACKNOWLEDGEMENTS}

This study was supported by the New Zealand Ministry of Agriculture and Fisheries and the Lincoln College Research Committee. Thanks are also due to Mr D.S. Rickard for providing the soil samples and pasture production data.

\section{REFERENCES}

Condron, L.M.; Goh, K.M. 1989. Effects of long-term phosphatic fertilizer applications on amounts and forms of phosphorus in soil under irrigated pasture in New Zealand. Journal of soil science 40: 383-395.

Condron, L.M.; Goh, K.M. 1990. Nature and availability of residual phosphorus in long-term fertilized pasture soils in New Zealand. Journal of agricultural science, Cambridge 114: 1-9.

Devine, J.R.; Gunary, D.; Larsen, S. 1968. Availability of phosphate as affected by duration of fertilizer contact with soil. Journal of agricultural science, Cambridge 71: 359-364.
Goh, K.M.; Condron, L.M. 1989. Plant availability of phosphorus accumulated from long-term applications of superphosphate and effluent to irrigated pasture. NZ Journal of agricultural research 32: 45-5 1 .

Jackman, R.N. 1964. Accumulation of organic matter in some New Zealand soils under permanent pasture. I. Patterns of change in organic carbon, nitrogen, sulphur and phosphorus. NZ journal of agricultural research 7: 445-479.

Mackay, A.D.; Wewala, G.S. 1990. Evaluation of partially acidulated phosphate fertilisers and reactive phosphate rock for hill pastures. Fertilizer Research 21: 149-156.

Nguyen, M.L.; Rickard, D.S.; McBride, S.D. 1989. Pasture production and changes in phosphorus and sulphur status in irrigated pastures receiving long-term applications of superphosphate fertiliser. NZ journal of agricultural research 32: 245-262.

Oniani, O.G.; Chater, M.; Mattingly, G.E.G. 1973. Some effects of fertilisers and farmyard manure on the organic phosphorus in soils. Journal of soil science 24: $1-9$.

Parfitt, R.L. 1980. A note on the losses from a phosphate cycle under grazed pasture. NZ journal of experimental agriculture 8: 215-217.

Perrott, K.W.; Mansell, G.P. 1989. Effect of fertiliser phosphorus and liming on inorganic and organic soil phosphorus fractions. NZ journal of agricultural research 32: 63-70.

Stewart, J.W.B.; Tiessen, H. 1987. Dynamics of soil organic phosphorus. Biogeochemisfry 4: 41-60. 